\title{
Estructura y distribución del poder en Arabia Saudí. Principales actores, instituciones y procesos de decisión
}

\author{
David Hernández Martinez ${ }^{1}$
}

Recibido: 05/10/2019 / Aceptado: 9/11/2019

Resumen. Arabia Saudí es uno de los países más relevantes de Oriente Medio y sus acciones tienen un alcance determinante en las dinámicas regionales. Bajo la estructura de una monarquía autoritaria, la Casa Saud ha desarrollado un Estado y organización social que responden exclusivamente a sus objetivos políticos. Este trabajo realiza un estudio de caso, analizando las correlaciones de fuerza dentro del reino, los actores e instituciones más relevantes en la distribución del poder y los espacios de conflicto entre las diversas facciones desde la constitución del reino en 1932 hasta la actualidad. La investigación busca responder cuáles son los factores internos que propician el dominio de la dinastía real y cuáles son sus debilidades. El propósito final es facilitar una mejor comprensión sobre el funcionamiento del gobierno y administración estatal.

Palabras clave: Arabia Saudí, poder, gobierno, wahabismo, Casa Saud.

[en] Structure and distribution of power in Saudi Arabia. Main actors, institutions and decisionmaking process

\begin{abstract}
Saudi Arabia is one of the most important countries in the Middle East and its actions have a decisive influence on regional dynamics. According to the structure of an authoritarian monarchy, House of Saud has developed a State and social organization that respond exclusively to its political objectives. This paper carries out a case study, analyzing the strength correlations within the kingdom, the most relevant actors and institutions in the distribution of power and spaces of conflict between the different groups from kingdom's constitution in 1932 to the current days. The research seeks to answer what are the internal factors that stimulate the royal dynasty's dominance and what are the most notorious regimen's weaknesses. The purpose is to facilitate a better understanding of the functioning of the Government and State Administration.
\end{abstract}

Keywords: Saudi Arabia, power, government, wahhabism, House of Saud.

Sumario. 1. Introducción. 2. Aspectos metodológicos y teóricos. 3. La categorización de la sociedad saudita. 4. La construcción del Estado moderno. 5. La distribución institucional del poder. 6. Conclusión.

Cómo citar: Hernández Martinez, D. (2020): Estructura y distribución del poder en Arabia Saudí. Principales actores, instituciones y procesos de decisión, en Cuadernos de Gobierno y Administración Pública 7-1, 15-25.

\section{Introducción}

El reino de Arabia Saudí tiene un peso político y religioso transcendental en Oriente Medio, el Magreb y la esfera musulmana. Las decisiones tomadas desde Riad en materia de política exterior y estrategia regional tienen un alcance notorio sobre las principales coyunturas del entorno. Los príncipes sauditas han sido capaces de establecer una posición hegemónica tanto dentro como fuera de su territorio, aunque existen numerosas corrien- tes que cuestionan tal poder. Desde la reunificación en 1932, la Casa Saud ha estado dirigiendo el país, dominando las principales instituciones y recursos y estableciendo un tipo de orden social acorde con sus intereses.

El oficialismo saudita intenta presentar una imagen homogénea y monolítica del país árabe, bajo la presunción de una imperante estabilidad y un escaso nivel de conflictividad. Pero la realidad del reino resulta más intricada que el panorama presentado desde la corona. La tarea esencial de la familia real por consolidar su auto-

\footnotetext{
Investigador postdoctoral

Universidad Autónoma de Madrid

davidhm26391@gmail.com
} 
ridad interna, estableciendo una administración estatal acorde con sus objetivos, ha estado en todo momento cuestionada desde diferentes posiciones. El liderazgo del rey y su clan es un proceso evolutivo en el que han tenido que superar diversas resistencias, dando lugar a un singular arquetipo político y organización de la vida social.

La más destacable característica del Estado saudita es la propia naturaleza de la nación y el poder político. Todos los elementos constitutivos del reino responden a las premisas y exigencias de la Casa Saud. No es un proceso histórico protagonizado por un pueblo o comunidad concreta, que termina manifestándose en la consecución de un tipo de gobierno y la cohesión social bajo unos estándares comunes, sino más bien se trata de la acción medida de una élite para asegurar su propia pervivencia. Todas las transformaciones producidas en Arabia Saudí en la historia reciente tienen como propulsores a los distintos monarcas, que han ejercido el cargo de forma autoritaria.

El rey y la dinastía Saud se encuentran en el centro de la vida política y social de Arabia Saudí, acompañados por el wahabismo, que es la rama religiosa oficial en el país y el primordial recurso legitimador de su preponderancia. El modelo establecido a principios del siglo $\mathrm{XX}$ aparentemente anula cualquier tipo de disidencia u oposición, pero la realidad es que dentro las fronteras sauditas el consenso político y social es bastante intrincado y difícil, sometido a constantes fallas y puntos de incipiente tensión.

La distribución del poder se hace respondiendo a las pretensiones del clan Saud, pero atendiendo también a las distintas sensibilidades, que condicionan la capacidad de los gobernantes de ejercer sus responsabilidades y la aplicación de las decisiones reales. El arraigo tribal y étnico aun fuertemente presente en el centro de la península arábiga induce a que los dirigentes sauditas no deban desestimar estos elementos, adaptando su programa político a factores como la diversidad de tradiciones y costumbres. La sociedad saudita tampoco se presenta como un eje inmóvil y cohesionado, ya que son crecientes las discrepancias y corrientes que postulan programas políticos divergentes, que ponen de una manera directa o indirecta en cuestión el status interno actual.

El establecimiento de una monarquía de tinte absolutista, junto con el férreo control que la corona ejerce sobre la mayoría de los aspectos internos, impide que exista una visión clara del funcionamiento estatal, las dinámicas que se establecen en torno al poder y la categorización de las discrepancias ideológicas. El presente artículo busca abordar esta compleja temática y sintetizar las características más relevantes de la política saudita, atendiendo a los actores más determinantes y las instituciones donde se plasma la autoridad, desde su constitución en 1932 hasta la actualidad. El propósito final es ofrecer una exposición más completa y precisa de las vicisitudes del reino, poniéndose énfasis en los temas $\mathrm{y}$ actores que marcan las discusiones centrales.

En una primera parte del trabajo, se analizan los agentes más destacados de la sociedad saudita. En el nivel más elevado estaría la Casa Saud y los estamentos del wahabismo, que controlan el país desde hace más de ochenta años. En una categoría aparte estaría el conjunto de la ciudadanía, que se encuentra en una situación totalmente dispar con respecto a sus dirigentes. Dentro de la comunidad saudita podemos distinguir varios tipos de fuerzas: la clase más afín al régimen y que ha conseguido prosperar entorno al círculo real; los chiitas sauditas que representan el segmento social de oposición más organizado; las corrientes más liberales y progresistas que propugnan una democratización del país y en frente las posiciones más conservadoras y rigoristas.

En una segunda parte, se disemina la estructuración del poder a través de las instituciones más importantes, centrada en la tarea del monarca y en cómo se reproducen sus decisiones en todos los ámbitos de Arabia Saudí. Además, se abordan las tensiones que surgen en torno al tipo de equilibrios que se establecen, por ejemplo, por el control de los más importantes recursos y cargos de responsabilidad. Estas desavenencias restringen el verdadero poder del rey y la dimensión de su cargo, que se ve redefinido por las presiones de diferentes sectores sociales y por las disputas en el seno de la propia familia real, incidiendo en cómo el reino se manifiesta en el exterior.

\section{Aspectos metodológicos y teóricos}

La investigación se desarrolla desde un prisma de análisis social y también bajo una perspectiva institucional. El primer ámbito sirve para abordar la heterogeneidad de la población y política saudita, categorizándolo en torno a la congruencia o divergencia de intereses de los distintos grupos, facciones y clases. El segundo aspecto permite abordar la estructuración real del poder en el reino y reflexionar sobre las tensiones existentes en los estamentos más elevados del Estado. Para convertir la explicación en una narrativa operativa se tienen que precisar conceptos recurrentemente utilizados en el texto.

Arabia Saudí es caracterizada como una monarquía absoluta, enmarcada en un Estado patrimonializado, que es desarrollado según un modelo económico rentista y con un funcionamiento clientelar. Los términos definen el sistema político y social existente y también el tipo de dinámicas que se producen dentro de la administración estatal y las relaciones entre ciudadanos y gobierno. Estos elementos permiten situar el reino saudita en un concreto marco conceptual, ayudando a destacar sus singularidades y posibilitando señalar analogías con respecto a otros países y regímenes políticos.

La nación saudita se organiza políticamente como monarquía absolutista desde su creación como Estado moderno en 1932, considerándolo como tal ya que el rey tiene competencias ilimitadas y ejercer su autoridad de tono absolutista. No existe la división de poderes, puesto que el monarca tiene las responsabilidades últimas en materia legislativa, judicial y ejecutiva (Yom y Gause, 2012: 76-77). Los príncipes sauditas no son solo figuras políticas sino también tienen un simbolismo religioso, encargados de la misión divina de proteger los Santos Lugares y extender una visión correcta del islam. La na- 
rrativa wahabita les proporciona un espacio mayor de legitimidad y valor moral.

La casa real se ha encargado de implementar un Estado señalado como patrimonial. Los recursos nacionales son partes esenciales del capital y propiedad de la dinastía. Los miembros más destacados ocupan los principales puestos de responsabilidad en el país, estando presentes en la mayoría de los niveles de la política y la sociedad. Todo el conjunto funciona con el propósito de responder a las necesidades y demandas del monarca y sus allegados (Ehteshami y Wright, 2007: 926-927). Los intereses nacionales son asociados directamente a los objetivos políticos de los Saud. La acción de las instituciones gubernamentales y públicas se hace con vistas a garantizar la perdurabilidad de la corona y el status privilegiado de los herederos al trono.

La monarquía absoluta y un Estado patrimonializado son dos rasgos comunes en muchas estructuras de poder de la zona de Oriente Medio, donde familias copan la cúspide de la política, amparando una articulación nacional destinada a servir exclusivamente a sus propósitos. La estabilidad interna se dirime según el grado de seguridad de la clase dirigente. Para esta finalidad ha sido indispensable la explotación de petróleo y gas (Okruhlik, 1999: 296-298), cuyas rentas sirven a los Saud para desarrollar el país e impulsar aquellos elementos estatales vitales para la supervivencia de la monarquía, aunque derive en una fuerte dependencia de estos recursos energéticos.

El control absoluto del reino por parte de los Saud tiene una implicación directa en el tipo de distribución de la riqueza y funcionamiento administrativo. El clientelismo como forma de relación entre gobernados y gobernantes (Hertog, 2007: 545-548), bajo un principio de dependencia y fragilidad de los primeros con respecto a los segundos, quienes se aseguran la lealtad y fidelidad de los ciudadanos con mecanismos más o menos explícitos de coacción y con un entramado de prebendas y ayudas discrecionales. La población saudita queda sujeta a la condición de asumir la anulación de derechos y libertades a cambio de que la corona les asegure cierto bienestar y seguridad.

\section{La categorización de la sociedad saudita}

Arabia Saudí es una monarquía absoluta donde la política está intrínsecamente ligada a las decisiones del rey. A pesar de la forma autoritaria en la que se rige el Estado, las dinámicas sociales y de poder están condicionadas por la correlación de fuerzas entre distintos actores y grupos. El país puede ser desgranado en dos tipos de esferas, por un lado, según su status dentro de la comunidad y proximidad con la corona; por otro, conforme al tipo de ideario ideológico y relación con las instituciones nacionales.

La sociedad queda caracterizada no solo por condicionantes económicos sino también por elementos políticos y religiosos. Se llegan a distinguir siete clases. Primero, los príncipes sauditas y el oficialismo wahabita que representan la élite nacional. Segundo, aquellos sec- tores más próximos a la corona con puestos intermedios en la administración o las grandes empresas. Tercero, los profesionales extranjeros altamente cualificados procedentes de Occidente $u$ otras áreas de la región. Cuarto, el ciudadano medio saudita, cuyo bienestar y satisfacción material están determinados por el grado de lealtad a la corona. Quinto, los sauditas más críticos con el poder de los Saud que son excluidos de la comunidad y perseguidos por las autoridades. Sexto, la población que sufre una condición de vida marginal y sometida a una pobreza sistemática. En último lugar, aquellos trabajadores poco cualificados provenientes la mayor parte de Asia Pacífico y del continente africano, que representan un grupo invisibilizado.

La dinastía Saud y el wahabismo son los dos grandes elementos cofundacionales del Estado. La familia real obtiene su status privilegiado tras la reunificación del reino en 1932, cuando el monarca Abdulaziz bin Saud consigue tras años de luchas tribales unir políticamente todos los territorios del interior de la península arábiga. Es una dinastía muy amplia, estimada cerca de los diez mil miembros (Taheri, 2012: 141-142), que controlan las instituciones y la economía del país. En un clan tan extenso surgen numerosas fricciones debido a dos grandes temas: la sucesión y las grandes políticas de Estado, que les lleva a agruparse según afinidades ideológicas e intereses por el trono.

El Estado se encuentra patrimonializado por los Saud, que han dado forma al régimen según sus prioridades políticas. Todas las acciones y medidas estatales responden exclusivamente a los intereses de la corona. Aunque existen profundas divergencias entre los miembros del clan, hay un consenso básico de salvaguardar la estabilidad interna y preservar la dinastía en el poder. El rey y sus familiares son referentes políticos y religiosos en el país (Al-Rasheed, 2004: 193-198), estando en el centro de la sociedad. Todo el reino queda subalterno a los requerimientos de la Casa real, cuyas figuras más destacadas determinan el devenir del país a través de su presencia en los grandes puestos políticos, en la esfera económica y a escala social.

El wahabismo representa el segundo pilar sobre el que se ha erigido la nación saudita. Desde el siglo XVIII, estos preceptos han estado ligados fuertemente a los objetivos políticos de los Saud (Habib, 2009: 57-59). El clan familiar se compromete a proteger la corriente religiosa de críticos y difundir su interpretación del islam, mientras que los estamentos wahabitas aseguran presentar ante las comunidades musulmanas un discurso congruente con la autoridad saudita. Por ello, llegan a ser la principal herramienta de adoctrinamiento y legitimación que tiene el gobierno de Arabia Saudí, que le sirve como prerrogativa para consagrarse como líderes morales del pueblo.

La rama wahabita tiene una alta presencia institucional en el reino, pero también tiene un considerable peso ideológico para el desarrollo político. El control de la educación, justicia y cultura quedan bajo la responsabilidad del oficialismo religioso. El wahabismo está muy presente en la sociedad saudita e influye directamente en las apreciaciones de los ciudadanos y en su relación con 
el poder. Además, marca la visión que tiene la corona sobre el rol que debe ejercer en el reino y también a escala internacional, siendo el vector sobre el que pivotan los principios más elementales.

En el segundo escalón de la jerarquización social se encuentra una clase privilegiada y cercana a la familia real y el wahabismo. Está formada por aquellos clanes y tribus que desde el momento de la reunificación se mantuvieron más leales a la corona saudita. Arabia Saudí sigue siendo un país con un fuerte componente tribal (Yamani, 2008: 143-145), que condiciona el desarrollo de las instituciones estatales. Este grupo también lo constituyen aquellos sauditas que consiguen medrar a través de la Administración pública y principales empresas nacionales. Son un segmento emergente afín al Gobierno, pero sin ningún tipo de vinculación dinástica con el rey. Son funcionarios, agentes del sector privado y tecnócratas que asumen cada vez más responsabilidades e influencia.

El tercer estamento social está compuesto por extranjeros occidentales y de países árabes del entorno, que representan a las corporaciones y delegaciones políticas que tienen diversos intereses en el país. Es una tendencia habitual en la mayoría de monarquías árabes del Golfo, por la cual los profesionales altamente cualificados y que copan las grandes labores del sector privado no son en su mayoría sauditas. El Gobierno ha emprendido varias iniciativas políticas para impulsar la de este tipo de puestos de trabajo y reducir la dependencia del talento llegado de fuera (De Bel-Air 2018). Componen un grupo privilegiado que no sufre directamente las restricciones del autoritarismo, aunque las relaciones con los nacionales son limitadas.

En el cuarto lugar se encuentran aquellos sauditas que pueden ser considerados como el prototipo de ciudadano medio. No poseen un status especial y tampoco tienen una cercanía notoria con la élite nacional, pero el Estado les garantiza un cierto nivel de vida y unos mínimos servicios como educación, sanidad o posibilidades laborales. Debido a la naturaleza rentista y clientelar del modelo saudita (Priego, 2017), el Gobierno se encarga de hacer una distribución de la riqueza bajo la premisa de sus intereses políticos, favoreciendo la dependencia económica de la mayor parte de los ciudadanos y reduciendo las posibilidades de que surjan movimientos contestatarios.

El quinto sector de la sociedad está conformado por los sauditas más críticos con el poder, cuyas movilizaciones y reivindicaciones no son toleradas por el Estado. La disidencia es cohibida en Arabia Saudí y tiene un fuerte componente social porque las autoridades promueven la exclusión social. Los opositores sufren represiones y condenas penales, o bien, tienen que salir del país y quedan señalados como elementos peligrosos para la estabilidad interna del país. La consecuencia más visible es que dejan de ser considerados ciudadanos con los mismos derechos y oportunidades que el resto.

En el sexto nivel están todos aquellos sauditas que viven en un estadio de carestía y penuria, siendo las clases más bajas del país. La pobreza es un problema enquistado y estructural de Arabia Saudí, que posee unas diferencias considerables entre las figuras más notables del reino y los sectores populares. Las cifras oficiales presentan un panorama distinto, en el que la realidad económica y social no es tan alarmante. Sin embargo, análisis internacionales advierten del alto número de la población, cerca de cuatro millones que vive bajo un umbral de miseria (Baker, 2013), sujetos a la solidaridad de congregaciones religiosas y algunas ayudas públicas. Son una parte del país que no es visible y cuya situación es escasamente atendida por las autoridades.

El último rango de la categorización social es la de la mano de obra extranjera encargada de trabajos de poca cualificación. A partir de la década de los setenta, las emergentes economías del Golfo comenzaron una serie de programas de modernización aprovechando los réditos del petróleo y gas. Para hacer frente a la demanda de trabajadores para sus economías (Silvey, 2006: 2629), buscaron empleados en países de Asia Pacífico y el continente africano destinados a tareas como la construcción de las grandes infraestructuras, así como para la hostelería o los cuidados del hogar. Muchos de ellos están ligados a regímenes laborales duros y con escaso reconocimiento legal.

El margen tan limitado de participación política y social en Arabia Saudí, genera que la comunidad quede muy marcada entre partidarios del régimen y opositores y críticos con la corona. La tendencia mayoritaria entre los sauditas es la de mantenerse bajo los cánones políticos señalados por la monarquía. Existen ciudadanos que lo hacen por convencimiento ideológico, en parte debido a la influencia del wahabismo en la legitimación del poder de los Saud (Al-Rasheed, 2012). Otros se decantan por no proyectar actitud discrepante por miedo a represalias y no perder ciertos derechos e incluso privilegios que les proporciona el Estado saudita. Finalmente, muchos nacionales se decantan por la indiferencia política, arraigados en el comportamiento pasivo y en la presunción de que solo el clan dinástico es capaz de cohesionar y estabilizar el reino.

La oposición en Arabia Saudí es muy diversa y responde a una gran amalgama de propuestas políticas y religiosas. El componente común entre todos estos actores es su descontento y desafección con el actual régimen, pero las divergencias entre ellos surgen por los propósitos de sus movimientos y los medios que proponen para lograrlos. Las facciones opositoras pueden ser categorizadas entre reformistas y radicales, ya que algunos presentan medidas renovadoras y otros defienden cambios drásticos del sistema. También queda divida entre las inclinaciones liberales y aperturistas y las posiciones conservadoras y rigoristas, dando pie a una fuerte polarización política.

Los chiitas sauditas han sido tradicionalmente el grupo opositor más organizado y visible dentro del reino. Se concentran, la mayor parte, en el este del país, en las zonas donde se hallan los principales yacimientos de petróleo y gas (Soage, 2017: 4-5). Sus reivindicaciones parten de que se sienten marginados y perseguidos por las autoridades por su confesión religiosa. El wahabismo oficial no tolera otro tipo de interpretaciones del islam y es especialmente crítico con el chiismo. Los 
príncipes sauditas ven en ellos un peligro constante de inestabilidad y una amenaza de posible injerencia iraní por el hecho de compartir los mismos preceptos de fe. Las protestas según demandas de menos represión y más atención y participación a favor de minorías como la chií.

La primavera árabe de 2011 no fue especialmente llamativa en Arabia Saudí, pero sí puso de relieve cierto descontento social con el funcionamiento gubernamental. Emerge un activismo político, muy prolífero en internet y redes sociales (Perlov y Guzansky, 2014), que denuncia la corrupción del sistema y que reclama mayores derechos y libertades individuales, protagonizado por las generaciones más jóvenes. El feminismo está cobrado un significativo protagonismo en los últimos años en Arabia Saudí, colocando en el centro del debate la condición de la mujer en el reino y presionando para un aperturismo y flexibilización de las pautas señaladas desde el Estado.

En el otro lado de la oposición se encuentran las posturas más conservadoras y rigoristas, que suelen ser tratadas con mayor tolerancia por la corona de los Saud que las liberales y democratizadoras. Este tipo de disidencia quedó manifestado en el asalto de la Gran Mezquita en 1979 o en las críticas a la presencia de militares estadounidenses en el territorio en 1991 (Lacroix, 2015: 175176). Pertenece la gran parte a la esfera del wahabismo oficial y sirven de herramienta de presión sobre el Gobierno para limitar el alcance de las reformas. Algunas de estas vertientes han dado pábulo a bandos más radicalizados y extremistas, ligados al auge del yihadismo en las últimas décadas.

\section{La construcción del Estado moderno}

Arabia Saudí como construcción política es en gran medida reciente, teniendo en cuenta que el país como identidad independiente y reconocida internacionalmente lo es desde el año 1932. El actual territorio saudita ha sido un espacio históricamente fragmentado, que durante siglos estuvo diseminado entre diferentes clanes y tribus. Desde el siglo XVIII, la familia Saud, que controlaba el centro de la península arábiga, hizo varios intentos infructuosos para propulsar una unión bajo un mismo reino y según los axiomas wahabitas. No será hasta la llegada de Abdulaziz bin Saud (reinado 1932-1953) cuando se produzca la constitución del nuevo Estado, tras varios años de incesantes luchas a principios del siglo XX contra otras dinastías también preponderantes de la zona.

La evolución del Estado saudita se realiza en consonancia con los intereses y necesidades de la familia Saud. Tiene un carácter totalmente patrimonial, en el que los príncipes sauditas controlan todos los ámbitos políticos y sociales y son quienes deciden los espacios y ritmos de transformación. En el desarrollo estatal se observan una serie de fases, que han ido definiendo la forma en que se estructura el poder y se acotan los márgenes de influencia (Hernández, 2019: 69-86). Primera etapa de consolidación, que corresponden con los rei- nados de Abdulaziz bin Saud y Saúd bin Abdulaziz entre 1932-1964; segundo período de ascenso, vinculado al Gobierno de Faisal durante 1964-1975; tercer ciclo de desarrollo, durante los mandatos de Jálid y Fahd en la década de los ochenta y noventa; un cuarto nivel de modernización, protagonizado por el rey Abdalá a principios del siglo XX y un último apartado de redefinición con Salmán desde 2015.

La primera etapa se caracteriza por dos facetas, reforzar el poder interno y escasa presencia internacional. Los Saud se preocupan primordialmente por establecer los pilares del nuevo Estado, que les permita controlar todo el territorio y afianzar la autoridad de la corona. La interpretación estricta del islam según el wahabismo les otorga la narrativa suficiente para justificar el imperio de un sistema jerarquizado y autoritario (Alrebh, 2017: 281-284). El rey y su familia tornan a figuras políticas y religiosas emblemáticas, convertidas en símbolos nacionales. La premisa básica es la de implementar instituciones que faciliten la tarea de la Casa Real de salvaguardar sus objetivos políticos. Los intereses nacionales se elaboran a partir de las presunciones y ambiciones de los príncipes sauditas. La inquietud más relevante en ese momento para el recién establecido Gobierno es la de evitar focos de conflicto en el interior del reino.

El reparto de responsabilidades se realiza atendiendo al poder absoluto del rey, pero también al necesario equilibrio dentro de la dinastía, el wahabismo y con otros clanes. El país queda dividido administrativamente en regiones gobernadas por los príncipes, encargados de implementar las decisiones del monarca por todo el territorio. El Gobierno solo está constituido por familiares directos y los ministerios son copados por el apellido Saud, que se extiende por un exiguo aparato estatal. Se crean los primeros cuerpos de seguridad interna, Guardia Nacional, ejército y Guardia Real, junto a la implementación de la policía religiosa (Espinosa, 2016). La economía pronto pasará a ser un componente transcendental para el desarrollo del propio Estado.

Los Saud deciden concentrar esfuerzos en la estabilidad del reino y en sacar los mayores réditos posibles al petróleo y gas. La política exterior no será un elemento significativo en esta primera fase. Arabia Saudí rehúye desempeñar un papel regional importante, supeditando sus acciones a escala internacional a la alianza con la potencia estadounidense (Domínguez de Olazábal, 2017: 8-9). Desde la corona comienza a potenciarse la constitución de grandes empresas nacionales, que tendrán su resorte más importante en Aramco, encargada de la producción y exportación de petróleo y gas de país. Los recursos son controlados por la familia real y pasan a ser una herramienta política más a su disposición, así como la fuente de ingresos básica para el régimen.

La segunda fase es la de ascenso del Estado saudita y los Saud en el plano político y regional, bajo las directrices de Faisal. El príncipe consigue deponer del cargo a su hermano Saúd bin Abdulaziz en 1964, preponderando la rama del clan dinástico que aboga por una profunda reforma del país. La corona había conseguido en apenas treinta años fortalecer un Estado y un Gobierno dentro de sus fronteras, pero lo cambios producidos en el en- 
torno con el panarabismo árabe y el liderazgo de Nasser supusieron una seria amenaza para la corona (Riedel, 2018: 32-34). En este período, la dinastía real buscará mejorar las capacidades estatales y ampliar la presencia internacional.

El rey Faisal impuso un funcionamiento más eficaz de la Administración estatal, dando una considerable prioridad a reforzar los dispositivos de seguridad y defensa, para evitar cualquier tipo de corriente revolucionaria. El petróleo ya no solo es el vehículo central que propulse el desarrollo del país, además es un elemento de disuasión de la política exterior de Arabia Saudí. Durante este reinado se constituyen los cimientos de la agenda nacional e internacional del Estado en las siguientes décadas, bajo la premisa de autoritarismo, ascenso regional y crecimiento económico.

La tercera etapa de la evolución tiene lugar durante los reinados de Jálid y Fahd en los ochenta y noventa, marcados por la ampliación de las estructuras estatales a nivel nacional y exterior. Arabia Saudí alcanza un rol destacado en Oriente Medio y la esfera musulmana en una época de grandes cambios regionales e internacionales. El Gobierno de los Saud consolida su faceta como líder de la zona (Wilson y Graham, 1994: 131-133), así como el interlocutor más estrecho de la Administración estadounidense. Se liga la seguridad, estabilidad y desarrollo del país con lo que pueda ocurrir en el entorno, prevaleciendo las prioridades de proteger los intereses nacionales.

En este período acontecen dos fenómenos notables dentro de las estructuras estatales. Por un lado, durante la década de los ochenta se concluye con el proceso de nacionalización de las grandes empresas nacionales. La actividad económica pasa a un control absoluto del Estado y, sobre todo, a una supervisión directa de los Saud. Por otro, tiene lugar la internacionalización del wahabismo (Enazy, 2009), a través de la financiación y soporte estatal a comunidades de creyentes, grupos religiosos y políticos por todo el mundo. Los cambios políticos en el interior del reino son escasos debido a que la monarquía muestra una considerable solvencia frente a tensiones internas.

El cuarto ciclo en el progreso del Estado de Arabia Saudí se da bajo el reinado de Abdalá bin Abdulaziz entre 2005 y 2015, aunque en la práctica estuvo como regente del país desde 1995 por los problemas de salud de su hermano Fahd. La etapa de finales del siglo XX y principios del XXI se define como de modernización por los impulsos que desde el gobierno se harán en varios ámbitos. Reformas políticas para mejorar la participación ciudadana, transparencia administrativa y ampliar derechos de grupos sociales como los de la mujer. Mejora y ampliación de las capacidades militares para reducir la dependencia defensiva de EEUU. Diversificación de las relaciones comerciales con terceros países e integración en los mercados internacionales.

El propósito de Abdalá fue intentar introducir reformas paulatinas en el funcionamiento estatal, pero sin afectar a la síntesis del régimen. Una flexibilización del sistema para adecuarlo a las nuevas circunstancias (McDowall, 2015). El alcance de sus políticas se topó con resistencias internas y los problemas derivados de la primavera árabe. Las iniciativas por liberalizar la economía y mejorar la operatividad del Estado se vieron obstaculizados por unas dinámicas arraigadas en la sociedad y élite del país, que limitaron los resultados de las medidas. Las revueltas de 2011 motivaron que la corona se decantase por restringir algunas de sus promesas de cambio político.

La quinta etapa está teniendo lugar durante el reinado de Salman, quien asume el poder del país en 2015 tras la muerte de su hermano Abdalá. Están siendo años de intensas reformas a todos los niveles en el Estado, bajo la visión del príncipe heredero Mohammed bin Salman sobre las nuevas prioridades nacionales ante las circunstancias internacionales y regionales (House, 2019: 13-15). Es una fase de redefinición de las capacidades y funcionalidad estatal. Existe una concentración de responsabilidades y decisiones en torno al joven dirigente, mientras se llevan a cabo un conjunto de programas que intentan mejorar las competencias económicas y militares del país.

Mohammed bin Salman es el principal responsable de las transformaciones anunciadas en el reino. El plan Saudi Vision 2030 recoge algunas aspiraciones de reforma, que pretenden profundizar en la línea de Abdalá antes de la primavera árabe. Desestatalizar la economía, reducir el peso de la administración y ampliar las fuentes de riqueza más allá del petróleo (Grand, 2018). También existe el interés de favorecer cierto aperturismo social y limitar el rigorismo religioso institucional. Estas pretensiones enfrentan a los miembros más notables de la familia real y ponen en cuestión la viabilidad de variaciones en el Estado sin alterar el régimen autoritario.

\section{La distribución institucional del poder}

La monarquía saudita es un régimen caracterizado como absoluta, patrimonializado rentista y clientelar. Estos rasgos determinan la forma en la que se ha desarrollado el Estado y el tipo de instituciones creadas para aplicar la autoridad real, que durante ochenta años han sufrido pocos cambios. Los espacios de influencia y la división de responsabilidades en el país vienen dados por la correlación de fuerzas dentro del seno del clan Saud, la relevancia ideológica del wahabismo, la presión de terceros actores y las necesidades del propio Gobierno frente a las circunstancias nacionales y regionales.

El rey asume una presencia política y religiosa destacada sobre el resto de la sociedad. No existe división de poderes y el dictamen final siempre depende de la voluntad del monarca, que no debe rendición de cuentas ante nadie. Sin embargo, Arabia Saudí no tiene una forma de gobierno personalista sino más bien una adjudicación del poder monopolizado por una dinastía concreta. El actor más relevante en la política nacional es la familia Saud, que está presente en la mayor parte de estamentos institucionales y ámbitos sociales. El consenso con el resto de príncipes y miembros del clan es una seña muy particular en el proceso de toma de decisiones. 
El nombramiento de Mohammed bin Salman como príncipe heredero, junto a la suma de cometidos que ha adquirido en tan poco tiempo, están provocando un creciente malestar en la familia real y los círculos más cercanos a la corona (Al-Rasheed, 2017: 6-7). Los reyes sauditas tienden a conciliar las diferentes posturas dentro del clan, bajo la premisa de que el poder no es un elemento individual sino de todo el colectivo Saud. El fundador del país, Abdulaziz bin Saud, tuvo en cuenta este principio a la hora de repartir competencias entre sus hijos, pero ahora Salmán rompe el consenso y el equilibrio entre las diversas sensibilidades de la dinastía. Una forma de actuar más directa y personalista se está imponiendo, dejando de lado la habitual dinámica de consenso y consulta.

En Arabia Saudí es costumbre que el rey se deje asesorar por los familiares más cercanos y figuras religiosas más relevantes del país. La finalidad de esta tarea es asegurar que las divisiones políticas de los Saud no debiliten el orden interno del régimen. El Jefe del Estado tiene atribuciones políticas ilimitadas, pero ello no es óbice para que todos los mandatarios busquen el beneplácito y consenso entre los miembros del clan. El reparto de cometidos y la participación de los príncipes en el poder han asegurado todo este tiempo la cohesión dinástica, así como la pervivencia del modelo. Romper este factor puede tener resultados imprevisibles para la estabilidad del reino.

La premisa de tomar decisiones consensuadas garantiza también que las sucesiones en el trono no sean un proceso traumático, logrando conservar grandes líneas de acción a lo largo del tiempo. Los monarcas suelen continuar y profundizar sobre las estrategias ya planteadas por sus antecesores en el cargo. No obstante, el rey Salmán y Mohammed bin Salman vuelven a marcar un inédito precedente (Vick, 2018), ya que están introduciendo importantes alteraciones en ámbitos tan sensibles como la política económica, exterior y de seguridad, dejando atrás postulados en los que se apoyó la gestión de Abdalá, asumiendo un enfoque que no tiene en cuenta otras perspectivas.

Las divergencias en cuanto a las grandes medidas y la línea sucesoria son los dos temas que polarizan las divergencias en el seno del clan. El rey Abdalá decidió en 2006 crear el Consejo de la Lealtad para esclarecer el procedimiento de sucesión y hacer partícipe de ello a las principales figuras de la dinastía real. En este espacio están representados 34 familiares directos, que supuestamente aprueban, de manera colegiada, los nombramientos para príncipe heredero y príncipe sustituto (Kern y Reed, 2012). No obstante, la acción del rey Salmán de dar preferencia a su hijo Mohammed bin Salman evidencia las debilidades de este órgano y la brecha abierta en el clan.

El rey tiene la potestad de configurar un gobierno con personalidades de su más estrecha confianza. El ejecutivo no responde como un centro de debate y consentimiento común, sino que cada ministro responde únicamente ante el monarca (Johnson, Lehman y Matthijs, 2002). El reparto ministerial tiende a atender tradicionalmente el peso de las diversas ramas familiares y las demandas del wahabismo oficial. La religión se reserva las carteras relacionadas con la educación, justicia y asuntos de fe, mientras los Saud procuran tener bajo su control directo áreas tan relevantes y sensibles para el régimen como las relacionadas con seguridad y defensa.

La escasa transparencia en un sistema como el saudita hace complicado vislumbrar el procedimiento de toma de decisiones y las posibles discusiones que surjan en torno a los grandes asuntos. Los cambios en el ejecutivo y otros altos cargos de la Administración se hacen siempre en nombre del rey, quien dispone la organización gubernamental y nombramientos en estamentos religiosos, militares, diplomacia o empresas estatales. El rey Salman y el príncipe Mohammed bin Salman han reforzado la tendencia iniciada por Abdalá de incorporar personal no perteneciente al linaje Saud a puestos importantes del Estado, dándole un toque más burocrático y menos patrimonial.

La Jefatura del Estado se disemina a través de diferentes ministerios y agencias, así como gobernaciones. Arabia Saudí queda administrativamente dividida en 13 regiones, dirigidas por miembros de la familia designados por el rey. Cada demarcación posee sus propios consejos consultivos locales, cuyas funciones son muy limitadas y simplemente están a disposición del Gobernador para asesorarle en temas específicos. Los municipios cuentan con sus propios consejos, elegidos a partir de 2005 por proceso electoral y con participación de mujeres desde 2015 (Chinchilla, 2016), aunque estos órganos no tienen ninguna función práctica más allá de aconsejar a las autoridades competentes.

El rey Abdalá alcanzó fama de reformista en parte por propiciar las primeras elecciones en Arabia Saudí y la participación de las mujeres en política. Sin embargo, el reino es un régimen absolutista y los cauces democráticos son muy reducidos. La participación ciudadana queda canalizada en el ámbito local y bajo un valor simbólico y consultivo (Aarts, 201: 33-34). Las cuestiones territoriales todavía se vinculan en la relación del monarca, príncipes y wahabismo con los grandes líderes tribales. La monarquía ha potenciado que el debate político quede imposibilitado de ser estructurado en organizaciones o partidos, soslayado por el componente religioso y étnico. Los ciudadanos todavía son actores políticamente pasivos y sin capacidad de decisión real.

El rey Salmán introdujo cambios en torno al funcionamiento del gobierno en los primeros meses de su reinado, creando dos nuevos Consejos que vendrían a complementar a los órganos ministeriales. El Consejo de Asuntos Políticos y Seguridad y el Consejo de Asuntos Económicos y Desarrollo surgen con el propósito de diseñar los planes de reforma y acción de la monarquía para los próximos años (Karasik, 2015). Ambos organismos están presididos por el príncipe Mohammed bin Salman y cuentan con la participación de ministerios y secretarías de área. Tienen como objetivo dar respuesta a los principales retos del país y los desafíos que afronta en el entorno.

Los dos Consejos suponen la confirmación del liderazgo del joven príncipe en los más altos puestos del Estado, ya que todas las decisiones relacionadas con 
política exterior, defensa o economía pasan por él antes de llegar al monarca. La supuesta finalidad consiste en dotar al ejecutivo de mayor operatividad y flexibilidad, aunque ello suponga limitar la participación y la vía consensual en el seno de la familia real. El resultado se ha traducido en la presentación del plan Saudi Vision 2030, un amplio programa de reformas que pretenden acelerar la modernización del país, y la iniciativa militar saudí en Yemen, que busca reafirmar la posición hegemónica del reino.

El Consejo de Asuntos Políticos y Seguridad está conformado por los ministros de Interior, Asuntos Exteriores, Guardia Nacional, Información, Asuntos Religiosos y los jefes de inteligencias y secretarios de Estado. El Consejo de Asuntos Económicos y Desarrollo lo componente Justicia, Petróleo, Finanzas, Trabajo, Vivienda, Economía, Comercio, Transporte, Comunicaciones y Tecnología, Sanidad, Servicio Civil, Agricultura, Educación, Medios, Asuntos Exteriores, Cultura y Hajj y Umrah y demás órganos competentes. La acción de estos organismos debería ser complementaria a la síntesis del Consejo de Ministros, pero la realidad muestra cierto conflicto estructural.

La disposición gubernamental del reino saudita muestra una tendencia de bicefalia en tres aspectos. Por un lado, el rey Salmán continúa siendo el Jefe del Estado y Gobierno, pero la tarea real está siendo ejercida por el príncipe heredero Mohammed bin Salman (Bsheer, 2018), actuando como un prototipo de primer ministro. Por otro, la labor de la administración estatal queda dividida en dos grandes áreas: seguridad-política exterior y economía-políticas sociales, sin apenas formularse conexiones entre ellas. Finalmente, en las grandes medidas planteadas para las siguientes décadas, los dos órganos de asuntos políticos y de desarrollo tienen una ocupación mayor que el propio Consejo de ministros, que está adquiriendo un valor testimonial y simbólico.

Desde la instauración del Estado moderno, la Casa Saud apeló a la Sharia y el Corán como la única constitución válida en el territorio, siempre bajo la estricta interpretación del wahabismo, que es capaz de desligarse de otras vertientes sunitas y de la escuela hanbali (Hossein, 2009: 12-15). El escaso entramado de leyes se construye a partir de tres círculos concéntricos: islam, tradiciones y decretos reales, que coexisten en un complejo e intricado equilibrio de objetivos. La formulación de normas queda reservada a las facultades del Jefe del Estado y Gobierno, asesorado por sus ministros y secretarios, no existiendo ninguna otra institución que está capacitada para esa función.

Los Gobernadores de las provincias y municipios pueden promulgar normativas para resolver problemas específicos de su zona, siempre y cuando no atenten contra los principios básicos. No hay cámaras en ningún nivel político en la que se estructure una cierta actividad parlamentaria válida. Como reflejan los libros sagrados, existe un Consejo de la Shura o Asamblea Consultiva (Dekmejian, 1998: 205-206), formada por 150 personalidades del país designadas por el Jefe del Estado, de los cuales una quinta parte deben ser mujeres. Esta cámara no tiene capacidad propositiva alguna y su tarea se limi- ta a responder únicamente a las consultas que el monarca pretenda realizar.

El Consejo de la Shura, como el resto de Consejo locales y municipales, cumple una triple función política al servicio de la corona. Primero, sirven para legitimar las decisiones tomadas por el rey y sus delegados al tener en cuenta las apreciaciones de resortes de la sociedad. Segundo, ayuda a transmitir una imagen de participación ciudadana y un cierto grado de aperturismo institucional de la monarquía. Finalmente, es una forma sencilla que tienen los príncipes sauditas para atender a las diversas fuerzas del país y responder a las sensibilidades de cada sector social, canalizando las posibles reivindicaciones y preocupaciones de los grupos afines al poder de los Saud.

La complejidad de los asuntos nacionales y la extensión de las funciones del Estado llevaron al rey Fahd a presentar en 1992 un compendio legislativo denominado "las leyes básicas", que intentaban dirimir el funcionamiento de la administración pública, la organización territorial y la funcionalidad del Consejo de la Shura (Wehrey, 2015). Los decretos reales siguen siendo el principal elemento vector de la política saudita, siempre fundamentada en el derecho islámico y las costumbres y tradiciones. Las leyes no pasan por el tamiz de una discusión pública e institucionalizada, quedando acotado el posible debate y la discrepancia a la influencia y advertencias que los miembros de la familia real, wahabismo y figuras destacadas del reino pueden hacer sobre el monarca.

El sistema judicial en Arabia Saudí es mucho más simple y está menos desarrollado que en otros regímenes de la zona. Los tribunales sauditas están enmarcados dentro del derecho islámico, los reales decretos, "las leyes básicas" y las normas tribales que aún imperan en las trece regiones (Maisel, 2009). El wahabismo sigue teniendo una posición preponderante en el ámbito jurídico, ya que tiene una alta capacidad de inferencia en el proceso de toma de decisiones, pero también en la propia ejecución de los preceptos. Los tribunales carecen por completo de cariz secular y son un espacio más donde imperan los axiomas religiosos. Solo el rey puede enmendar las sentencias emitidas por la justicia, puesto que él es también la máxima autoridad judicial en todo el reino.

La naturaleza netamente wahabita de la justicia solo es equilibrada por las reformas introducidas por monarcas anteriores y, sobre todo, las costumbres y tradiciones presentes en las distintas zonas del país y que todavía predominan en algunas tribus (Maisel, 2014: 112-113). La construcción del Estado se hizo en torno a una misma corona, pero manteniendo un difícil equilibrio territorial, que se traduce en un cierto grado de adaptabilidad del funcionamiento de la judicatura. Las sentencias se elaboran atendiendo a la particularidad de casa caso, la perspectiva religiosa del magistrado, la jurisprudencia y las connotaciones sectarias imperantes en cada provincia del país.

La unidad política propugnada por la monarquía de los Saud tiende a reducir los espacios de disensión dentro del marco legislativo y judicial. En el sistema estatal 
saudita se dan actualmente dos fases en cierta medida contradictorios. En primer lugar, existen gestos por parte del gobierno para ir facilitando la participación ciudadana y recoger la diversidad imperante en la sociedad. No obstante, la naturaleza autoritaria del régimen favorece toda una secuencia de homogenizar, que tiene su repercusión directa en la promulgación de leyes y en la acción de los tribunales, que sirve como instrumento para preservar en la estabilidad interna y el orden autoritario.

El modelo político instaurado por Abdulaziz bin Saud ha sufrido escasas permutas durante las últimas siete décadas. La inmutabilidad es una de las premisas básicas del Estado saudita, cuyo sistema está muy jerarquizado y el rey y la familia Saud son decisores políticos, referentes espirituales y máximas enseñas de la identidad nacional (House, 2012: 26-28). Los grandes debates quedan acotados a discrepancias dentro del clan y pocas veces son conocidos públicamente. El rey Salmán y Mohammed bin Salman intentan disminuir el peso de la presión dinástica y otros grupos cercanos al poder sobre la toma de decisiones, tornándolo en un proceso más discrecional.

\section{Conclusión}

La estructura y distribución del poder en Arabia Saudí se encuentra altamente jerarquizada, ocupando el rey y la familia Saud los principales puestos de responsabilidad en los ámbitos más significativos del país. A partir de este status especial se desarrolla un sistema social y político que intenta primar tres elementos: A) salvaguardar la autoridad moral del clan y de los preceptos wahabitas B) preservar la estabilidad interna del régimen y C) evitar injerencias externas y movimientos de cambio. Este modelo organizativo se ha ido construyendo durante más de ochenta años y muestra escasos atisbos de cambio, a pesar de ciertas reivindicaciones sociales.

La constitución de una monarquía absoluta, acompañada por un modelo de desarrollo rentista y clientelar bajo la influencia ideológica del wahabismo, ha permitido a los Saud implementar su liderazgo dentro del territorio por encima de las diferencias étnicas, culturales y políticas. La corona se convierte en el principio y final del sistema, garante del funcionamiento del mismo y de la cohesión de la propia sociedad. El rey y la élite política desempeñan el rol de máximos referentes nacionales cuya tarea es la de evitar la disgregación del reino. Estos principios impiden de forma elemental que el modelo saudita pueda tender de manera natural a procesos de profunda transformación.

El sistema de Arabia Saudí resulta positivo para los intereses de los dirigentes en tanto en cuanto les asegura el máximo control. Tienen la capacidad de monopolizar la vida política y social, asumiendo el gobierno de los recursos y capacidades. Pero la mayor debilidad de este tipo de estructura es su escasa flexibilidad y adaptabilidad. Todos los cambios introducidos han sido propiciados siempre desde arriba, como mecanismos de contención y prevención, anulando la participación real de la ciudadanía. Las modificaciones se producen según las previsiones gubernamentales y siempre asegurando que las bases del régimen puedan permanecer inalterables.

La estructuración del poder relega a la sociedad a un papel pasivo y marginal. La característica clientelar del Estado favorece que se premien a aquellos segmentos sociales que se muestran siempre leales a la corona. La crítica y oposición no solo es castigada y reprimida sino también aboca a una exclusión de la comunidad, negándoles poder participar de los escasos derechos y oportunidades que se ofrecen desde el gobierno. El espacio para el debate desaparece por la imposición del discurso oficial, que presenta cualquier tipo de modificación sistémica como una concesión real, que el rey ofrece a sus conciudadanos, pero no como respuesta a posibles reivindicaciones.

Pese a las difíciles circunstancias del reino, las resistencias dentro de la sociedad han emergido con fuerza y presentan programas alternativos a lo marcado desde el gobierno. Algunas corrientes transformadoras parten de agendas mínimamente reformadoras, donde aún se reconoce el status especial de la Casa Saud, hacia vertientes más radicales, que presentan unos objetivos absolutamente enmendadores del actual orden. La respuesta del Estado es la misma para todos los movimientos, a pesar de que las propuestas llegan a ser muy divergentes. Las demandas son percibidas desde los círculos de poder como fallas en el sistema y no oportunidades para regenerarlo.

El régimen saudita ha soportado las convulsiones internacionales y ciertas fricciones internas a lo largo del siglo XX y principios del XXI. Cada monarca ha destacado por introducir durante sus reinados pequeñas reformas sociales, económicas o jurídicas, pero cautelosamente y atendiendo a los requerimientos propios de la monarquía, no por presiones externas o las demandas de las ciudadanas. Esta tendencia hace prever que en el corto y medio plazo no tengan lugar grandes modificaciones en el equilibrio nacional, porque los Saud siguen mostrando una considerable resistencia y, tanto los factores endógenos como exógenos, tienen aún escasa fuerza para inducir cambios estructurales.

El poder en Arabia Saudí se cimienta sobre el control absoluto de los príncipes y la supervisión y adoctrinamiento del wahabismo. Plantear una distribución y organización diferente implica cuestionar el régimen vigente, lo que es descartado totalmente desde la jefatura del Estado. Ninguna de las principales figuras de los Saud llega a sugerir modificaciones amplias, que puedan conducir al país a un modelo político y social distinto. La mayor parte de los miembros de la dinastía y la élite nacional son conscientes de que perturbaciones tan profundas serían insostenibles para la actual monarquía, que presenta una clara dicotomía entre la certidumbre y seguridad de lo ya establecido y la inquietud por un panorama imprevisible y desconocido.

La duda recae en saber si es posible que exista una nación saudita más allá del régimen actual de los Saud. La monarquía fue la responsable de crear en 
torno a su poder toda una estructura estatal y determinar la organización social. Si la corona pierde capacidades o incluso termine desapareciendo puede suponer no solo el decaimiento del sistema, sino también el de la propia nación. Arabia Saudí se construyó en torno a la autoridad del rey, que fue capaz de unificar las distintas sensibilidades. Este tipo de organización deja poco espacio a cambios, porque cualquier tipo de movimiento en este sentido podría llegar a tener consecuencias impredecibles para el futuro de todo el reino.

\section{Bibliografía}

Aarts, Paul. W.H. (2011). "Maintaining authoritarianism: The jerky path of political reform in Saudi Arabia", en Journal Orient, vol. $52, \mathrm{n}^{\circ} 1$, pp. $29-43$.

Al-Rasheed, M. (2017). “King Salman and his son. Winning the US losing the rest”, LSE Middle East Centre Report, en september. Disponible en: http://eprints.lse.ac.uk/84283/1/KingSalmanandhisSon.pdf (Consultado, 12/07/2019).

Al-Rasheed, M. (2012). "No Saudi spring. Anatomy of a failed revolution”, Boston Review. A political and literary forum, en march. Disponible en: http://eprints.lse.ac.uk/57792/ (Consultado, 15/07/2019).

Al-Rasheed, M. (2004). "The capture of Riyadh revisited: Shaping historical imagination in Saudi Arabia”, en Al-Rasheed, M y Vitalis, R. (ed. Counter-narratives. History, contemporary society, and politics in Saudi Arabia and Yemen.). New York: Palgrave Macmillan.

Alrebh, A.F. (2017). “A wahhabi ethic in Saudi Arabia. Power, authority and religion in a muslim society”, en Sociology of Islam, vol. 5, no 4, no 5, pp. 278-302. DOI: 10.1163/22131418-00504001.

Baker, A. (2013). "Down and out in Saudi Arabia", Time en June 03. Disponible en: http://content.time.com/time/magazine/ article/0,9171,2144028,00.html (Consultado, 19/07/2019).

Bsheer, R. (2018): "How Mohammed bin Salman has transformed Saudi Arabia”, The Nation, en May 21. Disponible en: https://www.thenation.com/article/how-mohammed-bin-salman-has-transformed-saudi-arabia/ (Consultado, 11/07/2019).

Chinchilla, M. (2016): "Urnas sin volante: los derechos de las mujeres en Arabia Saudí”, El Orden Mundial, en 5 diciembre. Disponible en: https://elordenmundial.com/urnas-sin-volante-los-derechos-las-mujeres-arabia-saudi/ (Consultado, 22/07/2019).

De Bel-air, F. (2018). "Demography, migration and labour market in Saudi Arabia", Gulf labour markets, migration and population, en GLMM, n ${ }^{\circ}$ 5. Disponible en: http://gulfmigration.org/media/pubs/exno/GLMM_EN_2018_05.pdf The Middle East Journal, (Consultado, 20/07/2019).

Dekmejian, R. H. (1998). "Saudi Arabia's consultative council”, en vol. 52, nº 2, pp. 204-218.

Domínguez de Olazábal, I. (2017): “Arabia Saudí: Un gigante con pies de petróleo. Dinámicas internas y retos regionales”, Documento de Trabajo, en Opex, $n^{\circ}$ 83. Fundación Alternativas. Disponible en: https://www.fundacionalternativas.org/ observatorio-de-politica-exterior-opex/documentos/documentos-de-trabajo/arabia-saudi-un-gigante-con-pies-de-petroleodinamicas-internas-y-retos-regionales (Consultado, 22/07/2019).

Ehteshami, A y Wright, S. (2007). "Political change in the Arab Oil Monarchies: From liberalization to enfranchisement", International Affairs, en vol. 83, nº5, pp. 912-932.

Enazy, A. H. (2009). "Saudi Wahhabi Islam in the Service of Uncle Sam”, Middle East Institute, en October 1, 2009. Disponible en: https://www.mei.edu/publications/saudi-wahhabi-islam-service-uncle-sam (Consultado, 15/07/2019).

Espinosa, A. (2016): “Arabia Saudí quita poder a la policía religiosa y desata la euforia juvenil” en 13 abril. Disponible en: https:// elpais.com/internacional/2016/04/13/actualidad/1460540987 734917.html (Consultado, 22/07/2019).

Grand, S. (2018). "Saudi's vision 2030 continues to solicit concerns", en 11 september. Disponible en: https://www.atlanticcouncil. org/blogs/menasource/saudi-s-vision-2030-continues-to-solicit-concerns (Consultado, 14/07/2019).

Habib, J. S. (2009). "Wahhabi origins of the contemporary Saudi State", en Ayoob, M. y Kosebalaban, H. (ed.) Religion and politics in Saudi Arabia: Wahhabism and the state,. London: Lynne Rienner Publishers. 2009.

Hernández, D. (2019). La política exterior de Arabia Saudí en Oriente Medio tras la primavera árabe. Objetivos y estrategias regionales (2011-2016) Tesis Doctoral. Madrid: Universidad Complutense de Madrid.

Hertog, S. (2007). "Shaping the Saudi state: Human agency’s shifting role in rentier-state formation”, en , no 39, pp. $539-563$. DOI: $10.1017 /$ S0020743807071073

Hossein, K. E. (2009), “On a slow boat towards the rule of law: The nature of law in the Saudi Arabia legal system”, Arizona Journal of International \& Comparative Law en vol. 26, n 1, 2-47.

House, K. E. (2019) "Profile of a Prince. Promise and Peril in Mohammed bin Salman's vision 2030", en. "Profile of a Prince. Promise and Peril in Mohammed bin Salman's vision 2030", en Senior Fellow Paper, April. Disponible en: https://www. belfercenter.org/sites/default/files/2019-04/KEH2019/ProfileofaPrince.pdf (Consultado, 23/07/2019).

House, K. E. (2012) On Saudi Arabia. Its people, past, religion, fault lines and future. New York: Vintage Books, 2012.

Johnson, G., Lehman, G., y Matthijs, M. (2002). "Power and preservation the House of Saud", The Sais Europe Journal of Global Affairs en April 1. Disponible en: http://www.sais.journal.org/posts/power-and-preservation-in-the-house-of-saud (Consultado, 24/07/2019).

Kern, N y Reed, M. M. (2012). "The Crown Prince and the Allegiance Commission”, Foreign Reports Bulletin. en Middle East Policy Council. 21 June. Disponible en: http://www.mepc.org/commentary/crown-prince-and-allegiance-commission (Consultado, 23/07/2019).

Lacroix, S. (2015). "Understanding stability and dissent in the kingdom. The double-edged role of the jama' at in Saudi politics", en Haykel, B., Hegghamer, T., y Lacroix, S. (ed.). Saudi Arabia in transition. Insights on social, political economic and religious change. New York: Cambridge University Press. 
Maisel, S. (2014). "The new rise of tribalism in Saudi Arabia”, en Nomadic Peoples, vol. 18, n 2, pp. 100-122. DOI: https://doi. org/10.3197/np.2014.180207.

Maisel, S. (2009): “Tribes and the Saudi legal-system: and assessment of coexistence”, en Middle East Institute. October 1, 2009. Disponible en: https://www.mei.edu/publications/tribes-and-saudi-legal-system-assessment-coexistence (Consultado, 18/07/2019).

McDowall, A. (2015): "Saudi King Abdullah was a cautious reformer", en Reuters. January 23. Disponible en: https:// www.reuters.com/article/us-saudi-succession-abdullah-obituary/saudi-king-abdullah-was-a-cautious-reformeridUSKBN0KW00720150123 (Consultado, 18/07/2019).

Okruhlik, G. (1999). "Rentier wealth, unruly law, and the rise of opposition: The political economy of oil states", en Comparative Politics, vol. 31, no 3, pp. 295-315.

Perlov, O. y Guzansky, Y. (2014). "The social medita discourse in Saudi Arabia: The conservative and radical camps are the dominant voices", en INSS Insight. The Institute for National Security Studies, no 511, February 5. Disponible en: https://www. inss.org.il/publication/the-social-media-discourse-in-saudi-arabia-the-conservative-and-radical-camps-are-the-dominantvoices/ (Consultado, 18/07/2019).

Priego, A. (2017). "La reconfiguración de Arabia Saudí. Del modelo de los tres pactos a la Vision 2030", en Documento de Opinión. 16 de enero. Instituto Español de Estudios Estratégicos. Disponible en: https://dialnet.unirioja.es/servlet/ articulo?codigo=6057690 (Consultado, 13/07/2019).

Riedel, B. (2018): Kings and presidents. Saudi Arabia and the United States since FDR. Washington: Brookings Institution Press.

Silvey, R. (2006). "Consuming the transnational family: Indonesian migrant domestic workers to Saudi Arabia”, en Global Networks, vol. 6, nº1, pp. 23-40.

Soage, A. B. (2017). “¿Qué se esconde tras la guerra fría entre Arabia Saudí e Irán?”, en En Documento Opinión, 30 de junio. Instituto Español de Estudios Estratégicos. Disponible en: http://www.ieee.es/publicaciones-new/documentos-deopinion/2017/DIEEEO71-2017.html (Consultado, 17/07/2019).

Taheri, A. (2012). "Saudi Arabia: change begins within the Family", en America Foreign Policy Interests, no 34, pp.139-143. DOI: $10.1080 / 10803920.2012 .686725$

Vick, K. (2018). “The Saudi Crown Prince thinks he can transform the Middle East. Should we believe him?” en Time. April 5. Disponible en: https://time.com/longform/mohammed-bin-salman/ (Consultado, 11/07/2019).

Wehrey, F. (2015). “The Authoritarian resurgence. Saudi Arabi's anxious autocrats”, en Journal of Democracy, april 15. Carnegie Endowment for International Peace. Disponible en: https://www.journalofdemocracy.org/articles/the-authoritarianresurgence-saudi-arabias-anxious-autocrats/ (Consultado, 18/07/2019).

Yamani, M. (2008). "The two faces of Saudi Arabia”, en Survival, vol. 50, nº1, pp. 143-156.

Yom, S. L. y Gause III, F. G. (2012). "Resilient royals: how Arab monarchies hang on”, en Journal of Democracy, vol. 23, n 4, pp. 74-88. DOI: https://doi.org/10.1353/jod.2012.0062 